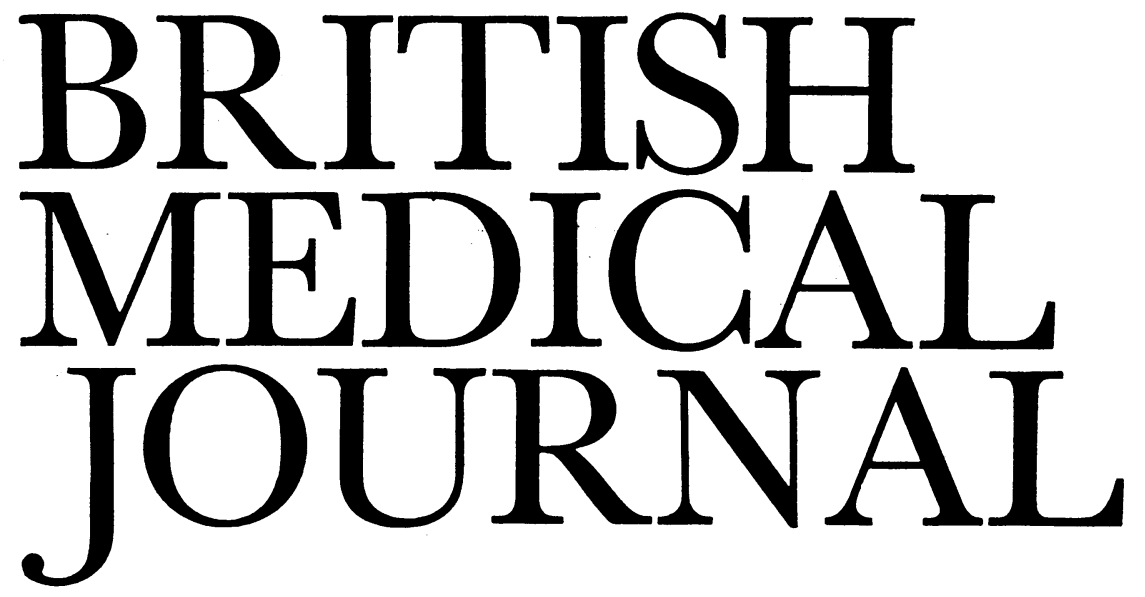

LONDON, SATURDAY 10 APRIL 1982

\title{
What is happening to peptic ulcer?
}

Most British gastroenterologists would probably say that they have noticed a decline in the frequency of peptic ulcer in recent years. How soundly based is this view, is it true of other countries with Western patterns of life, and what are the possible explanations?

Certainly large changes have occurred in the frequency of ulcers in the last 100 years. William Brinton ${ }^{1}$ wrote exclusively about gastric ulcer in his book published in 1867, presumably because duodenal ulcer was virtually an undescribed disease; but 30 years later series of patients with duodenal ulcer were being reported. Between the first and second world wars duodenal ulcer became more common than gastric ulcer; while gastric ulcer, formerly a disease which occurred predominantly in young women, developed the pattern that we now knowwith maximum impact on the elderly, both men and women. Duodenal ulcer seems to have reached a peak frequency in the middle 1950s, and both this and gastric ulcer may since have become less of a problem. ${ }^{2}$

Several possible explanations exist for these recent changes. The incidence of gastric and duodenal ulcer may have fallen; the advent of endoscopy may have brought greater diagnostic precision and so reduced the number of presumptive diagnoses; or new treatments may have altered the natural history of the diseases and reduced the need for hospital attendance or admission.

Reliable indices of ulcer frequency are difficult to define. Few patients die of ulcer; and death rates are much higher, perhaps 200 or 300 times higher, in elderly patients than in the young, reflecting the problems posed by associated disease. The overall numbers of patients admitted to hospital with ulcer are recorded in Britain and elsewhere, and operation rates and complication rates are also obtainable; but the individuals concerned form a special sample of the total population of patients with ulcers. Furthermore, those who are admitted may have had their disease newly diagnosed or may have had it for many years, so that true incidence rates cannot be obtained. Special surveys are needed to determine the incidence of ulcer in the community, but few such surveys have been conducted; and the increasingly intensive use of endoscopy as a diagnostic tool makes it virtually impossible to produce a fixed base against which figures produced at different periods could be judged.
The evidence available in Britain generally shows that peptic ulcer has become a less frequent problem. Overall mortality and admission rates for gastric and duodenal ulcer have fallen in the last 20 years in England and Wales. ${ }^{3}$ This fall has been more obvious in men than in women and has been particularly pronounced for duodenal ulcer in men in recent years. Perforation rates for gastric and duodenal ulcer have also fallen in men but not in women. Parallel findings in specific areas or groups of individuals include a fall in the overall number of ulcers diagnosed and in the perforation rates in York and Reading respectively, ${ }^{45}$ a fall in the incidence of duodenal ulcer in male doctors between 1947-50 and 1961-5, ${ }^{6}$ and a fall in sickness absence certified as due to ulcer between 1953-4 and 1971-2.7

Outside Britain, the death rate from peptic ulcer disease has fallen in Denmark since the $1950 \mathrm{~s},{ }^{8}$ though no change in the incidence of gastric or duodenal ulcer has been detected there. ${ }^{910}$ In the United States, however, various figures have shown a decline in the numbers of spells of incapacity due to gastric or duodenal ulcer, ${ }^{11}$ and a halving of diagnoses of ulcer in the work force and in the armed services from 1960 to $1972 .{ }^{12}$ The numbers of new cases of duodenal and gastric ulcer have also declined ${ }^{13}$; while hospital admission rates for duodenal ulcer in particular, and death rates for peptic ulcer in general, have fallen substantially. ${ }^{14}$ The conclusion must be that overall the frequency of ulcer, particularly duodenal ulcer, seems likely to have fallen, but that the extent of that fall is difficult to determine.

Ulcer dyspepsia can be treated effectively without the use of any objective diagnostic tests, and however much the purist may deplore that practice it is clearly widespread. In one study about a third of the patients prescribed cimetidine for the first time had it before a radiological or endoscopic diagnosis of ulcer had been made. ${ }^{15}$ Indeed, the diagnosis of ulcer is possibly delayed, perhaps indefinitely, while multiple courses of symptomatic treatment are given. Evidence that the advent of new drug treatments may indeed be changing the patterns of clinical practice is given by sudden falls in operation rates (against the background of already declining rates) in Britain and the United States since the introduction of $\mathrm{H}_{2}$-antagonists. ${ }^{16} 17$

If the frequency of ulcers has genuinely declined, what is the explanation? Susser and Stein ${ }^{18}$ suggested that generations born in the last quarter of the nineteenth century were 
exposed to maximum risks, which they carried through life, and that the risks have since receded. Consideration of agespecific ulcer perforation rates in Britain shows that, in general, reductions have been appreciable in the young; while in the elderly there have been smaller falls or even (as in middle-aged and elderly women with duodenal ulcer) an increase in perforation rates. Such differential changes are difficult to explain by a single cohort effect, particularly where a rise is now occurring in a group born after the end of the nineteenth century; and specific environmental influences need to be examined. Our knowledge of these is patchy. Smoking, the consumption of coffee and cola-type beverages, and other dietary factors (perhaps including low fibre intake) have been suggested as predisposing to ulcer, ${ }^{19-22}$ as has the use of nonsteroidal anti-inflammatory drugs. ${ }^{23}$ Milk consumption has been associated with protection. ${ }^{20}$ The relative importance of these and other factors is uncertain. If poor social conditions contributed to the development of ulcer in the past, what will the impact of high unemployment rates be now? There are many questions still to be answered.

\section{J S LANGMAN}

Professor of Therapeutics,

University of Nottingham,

City Hospital,

Nottingham NG5 1PB

${ }^{1}$ Brinton W. On the pathology, symptoms, and treatment of ulcer of the stomach. London: Churchill, 1857.

${ }^{2}$ Langman MJS. The epidemiology of chronic digestive disease. London: Edward Arnold, 1979.

${ }^{3}$ Coggon D, Lambert P, Langman MJS. 20 years of hospital admissions for peptic ulcer in England and Wales. Lancet 1981 ; :1302-4.

4 Pulvertaft CN. Peptic ulcer in town and country. British fournal of Preventive and Social Medicine 1959;13:131-8.

5 Sanders R. Incidence of perforated duodenal and gastric ulcer in Oxford. Gut 1967;8:58-63.

${ }^{6}$ Meade TW, Arie THD, Brewis M, Morris JN. Recent history of ischaemic heart disease and duodenal ulcer in doctors. $\mathrm{Br}$ Med $\mathcal{F}$ 1968;iii:701-4.

7 Taylor P. Sickness absence: facts and misconceptions. $\mathcal{F} R$ Coll Physicians Lond $1974 ; 8: 315-33$.

8 Sterup K, Mosbech J. Trends in the mortality from peptic ulcer in Denmark. Scand f Gastroenterol 1973;8:49-53.

- Bonnevie OE. The incidence of gastric ulcer in Copenhagen County. Scand $\mathcal{F}$ Gastroenterol 1975;10:231-9.

${ }^{10}$ Bonnevie OE. The incidence of duodenal ulcer in Copenhagen County. Scand $\mathcal{F}$ Gastroenterol 1975;10:385-93.

11 Almy TP, et al. Prevalence and significance of digestive disease. Gastroenterology $1975 ; 68: 1351-71$.

12 Mendeloff AI. What has been happening to duodenal ulcer? Gastroenterology $1974 ; 67: 1020-2$

${ }^{13}$ Vogt TM, Johnson RE. Recent changes in the incidence of duodenal and gastric ulcer. Am $\mathcal{F}$ Epidemiol 1980;111:713-20.

14 Elashoff JD, Grossman MI. Trends in hospital admissions and death rates for peptic ulcer in the United States from 1970 to 1978. Gastroenterology $1980 ; 78: 280-5$.

15 Colin-Jones D, Langman MJS, Lawson DH, Vessey MP. Post-marketing surveillance. In: Baron $\mathrm{JH}$, ed. Cimetidine in the 80 s. Edinburgh: Churchill Livingstone, $1981: 270-4$.

16 Wyllie JH, Clark CG, Alexander-Williams J, et al. Effect of cimetidine on surgery for duodenal ulcer. Lancet 1981 ; i:1307-8.

17 Fineberg HV, Pearlman LA. Surgical treatment of peptic ulcer in the United States. Trends before and after the introduction of cimetidine. Lancet $1981 ; \mathrm{i}: 1305-7$.

18 Susser S, Stein Z. Civilisation and peptic ulcer. Lancet $1962 ; \mathrm{i}: 115-9$.

19 Monson RR. Cigarette smoking and body form in peptic ulcer. Gastroenterology 1970;58:337-44.

${ }^{20}$ Paffenbarger RS, Jr, Wing AL, Hyde RT. Chronic disease in former college students; 13. Early precursors of peptic ulcer. Am $\mathcal{F}$ Epidemiol 1974;100:307-15.

21 Paffenbarger RS Jr, Wing AL, Hyde RT. Coffee, cigarettes and peptic ulcer. N Engl f Med 1974;290:1091.

22 Tovey FI. Duodenal ulcer and diet. In: Burkitt DP, Trowell HC, eds. Refined carbohydrate foods and disease: some implications of dietary fibre. London: Academic Press, 1975 :279-309.

${ }^{23}$ Thompson MR. Indomethacin and perforated duodenal ulcer. $\mathrm{Br} \mathrm{Med} \mathcal{F}$ $1980 ; 280: 448$.

\section{Is early antenatal attendance so important?}

The recognition that women who attend late for antenatal care experience a higher than average perinatal mortality rate has provoked much publicity designed to encourage them to attend early. Women who book late are less likely to be able to benefit from screening for serum alpha-fetoprotein, amniocentesis for chromosomal and other abnormalities, fetoscopy and fetal blood sampling, the early categorisation of risk factors including clarification of uncertain dates, and early recruitment to health education and mothercraft classes.

In an audit of antenatal care for 1975 a group from Aberdeen investigated the value of the first visit. ${ }^{1}$ Some salutary lessons were learnt. Late booking was common: only one-third of women had attended by the 12th week, and a quarter had still not attended by the 18th week. Much of the latter group consisted of single women or those with a prenuptial conception. But for those who did attend the clinic the recognition of serious problems by the staff was not good. Twenty-three per cent of serious medical conditions were not specially noted, and the previous birth of a growth-retarded infant $(<10$ th centile) was noted in only $32 \%$ of cases. Further, many of the problems in late pregnancy proved unpredictable. For instance, half the perinatal deaths had no readily identifiable risk factor at booking, and when patients were selected at the first visit for confinement in a non-specialist unit about half were transferred for delivery in the main hospital because of later complications-a dilemma that is widely recognised. ${ }^{2-4}$

The introduction and widespread adoption of certain antenatal screening procedures such as estimation of serum alphafetoprotein for the early detection of neural-tube defects pose some important problems against a background of late attendance. The experience of workers in a district general hospital in King's Lynn ${ }^{5}$ may well be shared by others. In two years they screened 3479 pregnant women, of whom eight were carrying fetuses with an open neural-tube defect. Four were anencephalics with very high alpha-fetoprotein values. Of the remaining four fetuses with neural-tube defects without anencephaly, only one was detected, one had normal amniotic fluid values, and two were missed. The King's Lynn group attributed these poor results not to the precision of the assay or to atypical scanning errors but to the fact that interpretation of the serum alpha-fetoprotein concentration is so critically dependent on gestational age that an error of one week at 16 weeks might lead to major errors. Though they conceded that estimation of gestational age might be improved by earlier attendance and by the use of newer scanners, they have abandoned this screening procedure.

The three questions that we have to ask ourselves are, How good is ultrasound in the management of these problems? Could these techniques have widespread validity ? and, What "fail-safe" procedures can be devised to minimise errors? Henry Ford once made a comment that rings true in this context. He said, "A scientific discovery is a fine thing in itself but it doesn't help the world till it's put on a business basis."

The availability within the past three years of high-resolution real-time scanning equipment which is portable enough to use in the antenatal clinic makes early screening for gestational age a feasible prospect, especially if the numbers booking are limited to about 10 for each session. Even when the mother has an empty bladder (essential for pelvic examination) crownrump lengths measured in this way correlated to a high degree with those using a conventional B-scanner. ${ }^{6}$ The observed 